\title{
The Challenge of Managing Fusiform Basilar Artery Aneurysms: From Acute Ischemic Stroke to a Massive Subarachnoid Hemorrhage
}

\author{
Sofia Bezerra ${ }^{a}$ Eduardo Casaroto $^{b}$ Monique Bueno Alves $^{c}$ \\ Leonardo lerardi Goulart ${ }^{c}$ Marcelo Annes ${ }^{c}$ \\ Gisele Sampaio Silva ${ }^{\text {b-d }}$ \\ a Pontifícia Universidade Católica do Rio Grande do Sul - PUCRS, and bintensive \\ Care Unit and 'Neurology Program, Albert Einstein Hospital, and dDepartment of \\ Neurology and Neurosurgery, Federal University of São Paulo, São Paulo, Brazil
}

\section{Key Words}

Fusiform basilar aneurysm · Ischemic stroke · Subarachnoid hemorrhage

\begin{abstract}
We present the case of a patient with acute brain stem ischemic stroke who was found to have a fusiform basilar aneurysm with a thrombus within the dilated vessel. Three days after the ischemic stroke, the patient had a massive subarachnoid hemorrhage and died. This case illustrates the difficulties in the acute management of ischemic events in patients with basilar fusiform aneurysms, because the natural history of this disease encompasses both bleeding and thrombosis.
\end{abstract}

\section{Introduction}

Dolichoectatic and fusiform aneurysms represent a small subset of cerebral aneurysms and are among the most difficult to treat [1]. The pathophysiology of fusiform cerebral aneurysms includes a disrupted internal elastic lamina and muscle layer that might be susceptible to mechanical injury by hemodynamic strain, causing progressive attenuation of the arterial wall [2]. The treatment of fusiform aneurysms of the basilar artery is challenging for several reasons, including the presence of perforating vessels, the proximity to the brain stem and the exiting cranial nerves, and the surgical approaches necessary to access the basilar artery [3-5]. We present the case of a patient with acute brain stem ischemic stroke who had a fusiform basilar artery aneurysm complicated by a 
massive subarachnoid hemorrhage. Our objective is to discuss the difficulties in the acute management of this disease, its potential treatments and complications.

\section{Case Report}

A 53-year-old man with a previous history of hypertension and obesity was admitted to our emergency department with sudden right hemiplegia, hemianopsia, and dysarthria within $2 \mathrm{~h}$ from symptom onset. His National Institutes of Health Stroke Scale (NIHSS) score at admission was 19, and he had no previous history of stroke or transient ischemic attacks. The patient's neurological symptoms progressively improved during the first hour after admission, with only a right facial palsy (NIHSS 2) remaining. A head CT at admission showed a hyperdense basilar artery, and a CT angiography (CTA) confirmed a basilar fusiform aneurysm with a thrombus within the vessel and no signs of acute

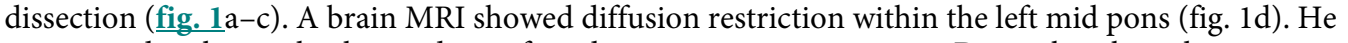
was treated with antiplatelets and transferred to our intensive care unit. Due to his clinical improvement, thrombolysis, endovascular procedures, and anticoagulation were deferred. Three days after admission, the patient suddenly became comatose. A head CT revealed an extensive subarachnoid hemorrhage in the basal cisterns and posterior fossa (Fisher grade 3; fig. 1e, f). The patient died the next day.

\section{Discussion}

Basilar artery fusiform aneurysms pose difficulties to treatment because, during the course of the disease, both bleeding and thrombosis can occur. In addition, bleeding may be a complication of a basilar artery fusiform aneurysm in patients initially presenting with brain ischemia, even when anticoagulation and thrombolytic treatments are not used, as happened in our patient [2-5].

Fusiform cerebral aneurysms can be divided into acute dissecting aneurysms, which usually cause subarachnoid hemorrhage or cerebral ischemia, and chronic fusiform or dolichoectatic aneurysms, which slowly enlarge with time and can be asymptomatic or associated with cranial nerve dysfunction, ischemic stroke, subarachnoid hemorrhage, pseudotumor, or hydrocephalus [6]. Although important for the treatment decisionmaking, the differentiation between a dissecting and a chronic fusiform aneurysm is often difficult, even with advanced neuroimaging techniques $[1,4,6]$. In our patient, regardless of the acute presentation of an ischemic event and posterior bleeding, no signs of dissection were seen on the CTA or the MRI/MRA of the brain.

More than half of large cerebral aneurysms with a diameter of $20 \mathrm{~mm}$ or more are known to have thrombi like the one seen in our patient [7]. The mortality rate of patients with fusiform basilar aneurysms is approximately $70 \%$ if the basilar artery has become occluded $[8,9]$. Conversely, the occurrence of hemorrhagic events is associated with the degree of ectasia of the basilar artery [10]. Anticoagulation therapy at conventional doses seems to increase the risk of intracranial bleeding $[11,12]$. The role of antiplatelet agents in promoting hemorrhagic strokes in such patients is less clear [10].

The treatment of such lesions can be a dilemma, as in the case described. In patients with vertebrobasilar dolichoectasia, the risk of brain ischemia is clearly higher than that of intracranial bleeding [13-15]. Considering that the current treatment risks can exceed the natural risk of basilar rupture or occlusion, a better understanding of the pathophysiology is required to help select patients at higher risk of hemorrhagic or ischemic events for invasive treatments $[4,5]$. 


\begin{tabular}{c|l|l|l}
$\begin{array}{c}\text { Case Reports in } \\
\text { HeIU:1:1) }\end{array}$ & $\begin{array}{l}\text { Case Rep Neurol 2011;3:50-53 } \\
\text { DOI: 10.1159/000324825 }\end{array}$ & $\begin{array}{l}\text { Published online: } \\
\text { February 21, 2011 }\end{array}$ & $\begin{array}{l}\text { O 2011 S. Karger AG, Basel } \\
\text { ISSN 1662-680X } \\
\text { www.karger.com/crn }\end{array}$ \\
\hline
\end{tabular}
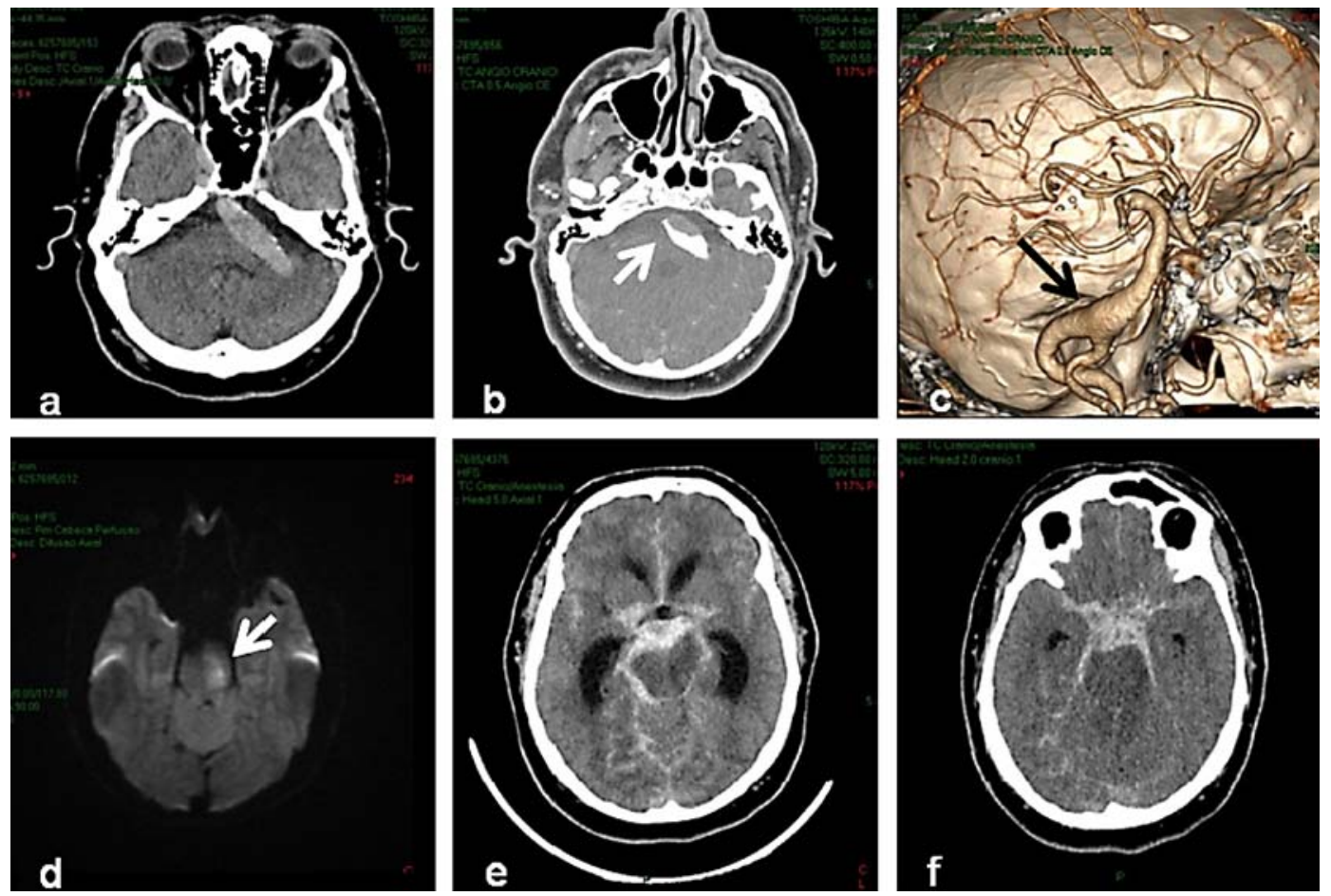

Fig. 1. a Noncontrast CT scan showing a hyperdense basilar artery. b CTA showing an intraluminal basilar thrombus. c CTA reconstruction showing a fusiform basilar aneurysm. d Brain magnetic diffusion-weighted resonance imaging showing an acute pontine infarction. e, $\mathbf{f}$ Noncontrast CT scans showing a diffuse subarachnoid hemorrhage (Fisher grade 3 ). 


\begin{tabular}{l|l|l|l} 
Case Reports in & $\begin{array}{l}\text { Case Rep Neurol 2011;3:50-53 } \\
\text { DOI: } 10.1159 / 000324825\end{array}$ & $\begin{array}{l}\text { Published online: } \\
\text { February 21, 2011 }\end{array}$ & $\begin{array}{l}\text { ○ 2011 S. Karger AG, Basel } \\
\text { ISSN 1662-680X } \\
\text { www.karger.com/crn }\end{array}$ \\
\hline
\end{tabular}

\section{References}

1 Anson JA, Lawton MT, Spetzler RF: Characteristics and surgical treatment of dolichoectatic and fusiform aneurysms. J Neurosurg 1996;84:185-193.

2 Boeri R, Passerini A: The megadolichobasilar anomaly. J Neurol Sci 1964;11:475-484.

-3 Echiverri HC, Rubino FA, Gupta SR, Gujrati M: Fusiform aneurysm of the vertebrobasilar arterial system. Stroke 1989;20:1741-1747.

-4 Higashida RT, Smith W, Gress D, Urwin R, Dowd CF, Balousek PA, Halbach VV: Intravascular stent and endovascular coil placement for a ruptured fusiform aneurysm of the basilar artery. Case report and review of the literature. J Neurosurg 1997;87:944-949.

-5 De Georgia M, Belden J, Pao L, Pessin M, Kwan E, Caplan L: Thrombus in vertebrobasilar dolichoectatic artery treated with intravenous urokinase. Cerebrovasc Dis 1999;9:28-33.

-6 Iwama T, Andoh T, Sakai N, Iwata T, Hirata T, Yamada H: Dissecting and fusiform aneurysms of vertebrobasilar systems. MR imaging. Neuroradiology 1990;32:272-279.

7 Whittle IR, Dorsch NW, Besser M: Spontaneous thrombosis in giant intracranial aneurysms. J Neurol Neurosurg Psychiatr 1982;45:1040-1047.

8 Watanabe T, Sato K, Yoshimoto T: Basilar artery occlusion caused by thrombosis of atherosclerotic fusiform aneurysm of the basilar artery. Stroke 1994;25:1068-1070.

-9 Archer CR, Horenstein S: Basilar artery occlusion: clinical and radiological correlation. Stroke 1977;8:383-390.

10 Passero SG, Calchetti B, Bartalini S: Intracranial bleeding in patients with vertebrobasilar dolichoectasia. Stroke 2005;36:1421-1425.

-11 Rabb CH, Barnwell SL: Catastrophic subarachnoid hemorrhage resulting from ruptured vertebrobasilar dolichoectasia: case report. Neurosurgery 1998;42:379-382.

12 Hart RG, Boop BS, Anderson DC: Oral anticoagulants and intracranial hemorrhage. Facts and hypotheses. Stroke 1995;26:1471-1477.

13 Pessin MS, Chimowitz MI, Levine SR, Kwan ES, Adelman LS, Earnest MP, Clark DM, Chason J, Ausman JI, Caplan LR: Stroke in patients with fusiform vertebrobasilar aneurysms. Neurology 1989;39:16-21.

14 Passero SG, Rossi S: Natural history of vertebrobasilar dolichoectasia. Neurology 2008;70:66-72.

15 Nishizaki T, Tamaki N, Takeda N, Shirakuni T, Kondoh T, Matsumoto S: Dolichoectatic basilar artery: a review of 23 cases. Stroke 1986;17:1277-1281. 